\title{
PRODUÇÃO DE TEXTOS EM MATERIAL DIDÁTICO PARA O ENSINO MÉDIO: QUESTÕES SOBRE SUBJETIVIDADE E GÊNEROS'
}

\section{WRITING IN TEXTBOOK FOR HIGH SCHOOL: ISSUES ON SUBJECTIVITY AND GENRES}

\section{Marina Célia Mendonça*}

\section{RESUMO}

O objetivo deste artigo é discutir os modos de presença da subjetividade/ intersubjetividade no discurso sobre a produção textual em Língua Portuguesa em material didático brasileiro direcionado ao Ensino Médio e aprovado no Plano Nacional do Livro Didático (PNLD) de 2018, relacionando essa presença (ou ausência) com as práticas de escrita de gêneros. Inicialmente, são discutidos estudos das ciências da linguagem, com enfoque nas pesquisas realizadas no Brasil que colocam em evidência a subjetividade e/ou a intersubjetividade na relação com a textualidade. Na sequência, aponta-se a incorporação feita em documentos oficiais do discurso desenvolvido no contexto científico. Em seguida, analisa-se, a partir da perspectiva dos estudos bakhtinianos, propostas de produção escrita da coleção didática selecionada e do Manual do Professor que acompanha cada volume da coleção. Na análise, são consideradas as noções de autoria, indícios de autoria, protagonismo e gênero.

Palavras-chave: produção de texto; subjetividade; gêneros

\section{ABSTRACT}

The aim of this paper is to discuss the presence of subjectivity/intersubjectivity in the discourse on writing in Portuguese Language in a Brazilian High School textbook that was approved in the Plano Nacional do Livro Didático - 2018 (PNLD). This presence (or absence) will be related to genre writing practices. Initially, scientific studies on language are discussed, focusing on Brazilian researches that relate subjectivity and/or intersubjectivity with textuality. Then, the incorporation by official documents of the scientific discourse on language is discussed. Finally, from the perspective of Bakhtinian studies, textbook writing proposals are analyzed with the Teacher's Manual that accompanies the textbook. In the analysis, the concepts of authorship, vestiges of authorship, protagonism and genre are considered.

Keywords: writing; subjectivity; genres.

\footnotetext{
* Universidade Estadual Paulista, UNESP, Araraquara, SP, Brasil. marina.mendonca@unesp.br.

Orcid: http://orcid.org/0000-0002-5712-2346

1. Este trabalho é resultado de pesquisa de Pós-doutorado desenvolvida no Programa de Pesquisador de Pós-Doutorado da Unicamp (2018-2019), sob supervisão do Prof. Dr. Sírio Possenti.
} 


\section{INTRODUÇÃO}

O objetivo deste artigo é discutir os modos de presença da subjetividade/ intersubjetividade no discurso sobre a produção textual em Língua Portuguesa em material didático brasileiro direcionado ao Ensino Médio e aprovado no Plano Nacional do Livro Didático (PNLD), em sua versão de 2018, relacionando essa presença (ou ausência) com as práticas de escrita de gêneros. Para tanto, são analisadas propostas de produção escrita em uma coleção didática direcionada ao Ensino Médio - Veredas da Palavra (ALVES, MARTIN, 2016a, 2016b, 2016c) -, o Manual do Professor que é anexado à coleção, bem como comentários das autoras que acompanham as propostas, direcionados aos professores. Verifica-se em que medida as atividades de produção textual escrita atualizam o discurso das ciências de linguagem (Linguística, Linguística Aplicada) e de documentos oficiais sobre a subjetividade/intersubjetividade na produção textual e sua relação com o texto e/ ou o gênero.

A base teórica que orienta as análises desenvolvidas é a obra de Bakhtin e o Círculo, em especial M. Bakhtin (2000 [1952-1953]; 2010 [1920-1924]), Volochínov (2013 [1930]) e Volóchinov (2017 [1929]). São mobilizadas, principalmente, as concepções de diálogo, gêneros do discurso, enunciado concreto, tema e significação. Nessa perspectiva, o enunciado é constituído dialogicamente em um horizonte apreciativo específico, na interação social (VOLOCHÍNOV, 2013 [1930]; VOLÓCHINOV, 2017 [1929]). Ele é uma resposta à enunciação do outro, uma contrapalavra marcada pelos valores e ideologias que constituem os discursos envolvidos no processo: "Cada enunciado é um elo da cadeia muito complexa de outros enunciados" (BAKHTIN, 2000 [1952-1953], p. 291). O discurso, constituído pelo discurso-outro, produz sentido nessa forma sempre particular de constituição (num gênero de discurso, numa esfera de atividade e num horizonte apreciativo específico) e se manifesta como resposta a esse outro.

Dessa maneira, as análises discursivas que tomam por baliza teórica o pensamento de Bakhtin e o Círculo têm destacado a produção de sentido dos enunciados em determinados gêneros do discurso e suas relações na esfera de atividade em que se produzem. Essas esferas (ou campos), na obra do Círculo, são espaços sócio-histórico e ideologicamente concebidos, onde se dá a interação social por meio de signos ideológicos. Conforme Volóchinov (2017 [1929], p. 94), "Cada campo de criação ideológica possui seu próprio modo de se orientar na realidade, e a refrata a seu modo. Cada campo possui sua função específica na unidade da vida social." 
Essas esferas não são concebidas como um todo isolado - a análise busca perceber nelas o movimento do diálogo, que é a categoria central e balizadora das análises nessa perspectiva. Assim, as esferas são colocadas em relação, de forma que se busca perceber como elas se influenciam, se atualizam e como, nelas, enunciados se constituem e se (re)configuram. Dessa maneira, as esferas que este artigo pretende colocar em relação (científica e didático-pedagógica), por refratarem a realidade de maneira específica e por terem funções diferentes na sociedade, "historicizam" a seu modo o discurso que produzem.

Da mesma forma, é importante para este trabalho a noção de gêneros do discurso - "formas discursivas de comunicação ideológica" / "grupo de formas homogêneas", conforme Volóchinov (2017 [1929], p. 109); "tipos relativamente estáveis de enunciados", segundo Bakhtin, (2000 [1952-1953], p. 279). Esses gêneros, como as esferas, se interpenetram e se movimentam, no trabalho ideológico de refração da organização social. Entendidos em consonância com as noções de enunciado concreto e esfera de atividade, os gêneros discursivos, em sua forma composicional e estilo, são afetados pelos valores axiológicos que envolvem a interação social, ou seja, pela forma arquitetônica (o eu para mim, o eu para o outro, o outro para mim) - Bakhtin (2010 [1920-1924]).

Apesar de as condições histórico-ideológicas definirem possibilidades de dizer/interpretar (o que dá aos gêneros uma "estabilidade histórica"), essas possibilidades são, na perspectiva bakhtiniana, espaços de contínua (re/des) construção. A concepção de linguagem adotada pelos autores do Círculo prevê essa estabilidade histórica e esse atualizar no acontecimento da enunciação - aos quais Volóchinov (2017 [1929]) chama de significação e tema, respectivamente. A noção de tema, nessa perspectiva, como o sentido do enunciado em situações precisas - "O enunciado só possui um tema ao ser considerado um fenômeno histórico em toda sua completude concreta. É isso que constitui o tema do enunciado" (VOLÓCHINOV, 2017 [1929], p. 228) -, é importante para este artigo, já que o interesse é analisar, no contexto de uma coleção didática, como se atualiza, em um novo tema, o discurso sobre o sujeito em sua relação com as atividades de escrita. Neste trabalho, em especial, é discutida a atualização das noções de autoria, indícios de autoria, protagonismo/protagonista e como a noção de gênero, na coleção didática em análise, se relaciona com a questão da subjetividade e intersubjetividade na prática de escrita.

O artigo se organiza da seguinte forma. Inicialmente, são discutidos estudos desenvolvidos nas ciências da linguagem, com enfoque nas pesquisas realizadas no Brasil, no interior da Linguística e da Linguística Aplicada, que colocam em 
foco a subjetividade e/ou a intersubjetividade na relação com a textualidade. Nesta primeira seção, são aproveitados alguns trabalhos já desenvolvidos por mim e ampliados em seu escopo, abarcando as décadas de 1970 a 2010. Na sequência, discutimos a incorporação que é feita, em documentos oficiais direcionados ao Ensino Médio, do discurso desenvolvido no contexto científico - incorporação que interfere na produção de materiais didáticos, nosso objeto neste trabalho. Enfim, na seção que antecede as conclusões, analisamos propostas de produção escrita na coleção didática selecionada e no Manual do Professor que acompanha cada volume da coleção, bem como comentários das autoras, direcionados aos professores.

Enfim, é importante dizer que, no Capítulo 4 da Unidade 1, no Volume 1 da coleção, as autoras apresentam uma sumária exposição sobre a noção de gênero e utilizam a expressão gênero textual (e não gênero discursivo) (ALVES; MARTIN, 2016a, p. 73). Porque, neste artigo, não nos propomos uma discussão aprofundada das diferenças entre as diversas perspectivas sobre os gêneros, e porque as autoras assumem uma perspectiva diferente da que adotamos aqui, optamos por grafar somente "gênero(s)" em grande parte do trabalho, inclusive no título - com exceção de situações em que é importante distinguir as abordagens para a discussão que fazemos aqui. Destacamos que essa opção não deve ser compreendida como uma não consideração das importantes diferenças entre abordagens teóricas e suas consequentes adaptações para a esfera didático-pedagógica. Nas considerações finais, voltaremos a esta questão.

\section{SUBJETIVIDADE E/OU INTERSUBJETIVIDADE E AS PRÁTICAS DE ESCRITA: CONSIDERAÇÕES SOBRE ESSE DISCURSO EM CONTEXTO CIENTÍFICO}

Os estudos linguísticos sobre a textualidade, no Brasil, desde o final da década de 1970, têm destacado a relação entre o texto e a subjetividade, seja em pesquisas sobre a intersubjetividade na produção textual e a contextualização sóciohistórica do enunciado, seja em trabalhos acerca da identidade e subjetividade nos estudos sobre letramentos, seja na discussão sobre a autoria na produção textual.

Consideremos alguns estudos sobre as relações entre o eu e o outro/Outro nas produções escritas escolares. Primeiramente, é preciso destacar trabalhos nas décadas de 1970, 1980 e 1990 em que se discute o "esvaziamento da atuação do eu sobre o outro nessas atividades" (MENDONÇA, 2015). Os resultados mais visíveis desse "esvaziamento", na escrita escolar, eram, entre outros problemas, estratégias de preenchimento (DE LEMOS, 1977, 1988), modelos estruturais e clichês (GERALDI, 1984, 1991), argumentação com estereótipos, noções 
confusas e expressões de totalidade indeterminada (PÉCORA, 1977, 1983), falta de informatividade (COSTA VAL, 1994 [1991]). Em Mendonça (2015), comentamos esses trabalhos, os quais se desenvolveram em diferentes perspectivas da Linguística, contudo tinham em comum o fato de apontarem para estratégias textuais e/ou discursivas presentes na produção textual escolar que eram indício desse esvaziamento.

Pécora (1983), analisando textos dissertativos produzidos por candidatos em um concurso vestibular e por alunos de um curso universitário, argumenta que os problemas encontrados são frutos das condições de produção em que se dá a escrita em contexto escolar, que tenderiam a retirar da linguagem sua qualidade de ação intersubjetiva, sendo que o processo escolar produziria uma falsificação das condições de aprendizado da escrita, desvinculando-a do empenbo pessoal de atuação sobre o interlocutor.

De Lemos também realiza estudo na década de 1970 sobre redações de vestibular e, em trabalho direcionado a professores - publicado, em coletânea, pela Secretaria de Educação do Estado de São Paulo (DE LEMOS, 1988) -, afirma que os problemas do discurso escrito nos textos que analisa resultam de operações de "preenchimento de uma estrutura vazia" (que ela chama de estratégias de preenchimento) a qual corresponde a um modelo estereotipado que o autor tem do texto dissertativo escolar, operações que levariam esse autor a manter um diálogo "estereotipado" com seu interlocutor. A autora já introduz, a partir inclusive de trabalho de Bakhtin (que ela cita), a ideia de que também o texto escrito se constitui em um diálogo com o outro; ela aponta para a complexidade desse outro no contexto escolar, pois seria fruto de sobreposições de imagens/representações que são específicas à modalidade escrita, por oposição ao discurso oral, e à situação escolar de produção textual .

Também Costa Val (1994 [1991]) toma por objeto textos dissertativos produzidos em prova de vestibular. A pesquisadora conclui que a falta de informatividade é um dos problemas mais recorrentes nessas produções textuais e, considerando-a como fator de textualidade construído pelo autor tendo em vista o leitor, em processo interlocutivo, conclui que nos textos analisados falta diálogo significativo com o outro. Como os outros autores citados, entende que a escola brasileira falhava no trabalho com essa interlocução quando do processo de ensino/ aprendizagem da escrita.

Geraldi (1984) critica a transformação do texto em redação em contexto escolar, transformação que se daria quando, nas atividades de produção de textos, se construiria uma situação em que a função-aluno (e não o autor) escreve uma redação (um modelo estereotipado, e não um texto) para a função-professor (e não o leitor); dessa 
forma não se teria, nesse processo de escrita, um autor que produz um texto para um interlocutor/leitor interessado no que é enunciado. Assim, a escolarização da escrita (ou seja, a artificialidade de escrita do texto, desvinculado da relação de interlocução com um leitor efetivo e da relação com uma situação concreta de uso linguístico e com gêneros discursivos específicos) não permitiria que o estudante se colocasse como autor de um texto que é espaço de ação intersubjetiva e de constituição de subjetividade. Assim, Geraldi $(1984,1991)$ tem participação importante na questão de ensino/aprendizagem da produção textual no Brasil pois avança na discussão de essa produção ser espaço de construção de estereótipos e esvaziamento de interação entre o eu e o outro.

Outro enfoque acerca da relação do sujeito com o outro/Outro na escrita escolar aparece na abordagem do texto como processo (com etapas como planejamento, revisão feita pelo próprio autor durante e após a escrita, revisão feita pelos interlocutores, reescrita) tal como desenvolvida por pesquisadoras brasileiras - Fiad, Mayrink-Sabinson (1991) e Abaurre, Fiad, Mayrink-Sabinson (1997). Esses estudos foram discutidos por mim em outros trabalhos (MENDONÇA, 2015; 2019) e neste artigo, considerando os seus objetivos, destaco que o planejamento, a revisão, a reescrita são tomados nesses trabalhos como procedimentos no processo de escrita que permitem perceber indícios da constituição da autoria do escrevente, esta constituição passando necessariamente pela relação desse escrevente com seu interlocutor - mãe/pai, professor etc. Segundo seus estudos, alguns episódios de refacção textual são indícios (pistas, dados singulares) que "dão visibilidade ao trabalho do sujeito em seu processo de constituição de uma relação particular com a linguagem e com sua representação escrita" (ABAURRE; FIAD; MAYRINK-SABINSON, 1997, p. 8). Nesse processo, o papel do outro (interlocutor) é fundamental. A reescrita/ refacção é entendida por elas como um processo que se dá a partir da participação do outro e para dizer melhor para o outro o que se deseja dizer. Podemos dizer que a função da reescrita, nessa perspectiva, é o escrevente dizer melhor o que quer dizer, ou seja, manifestar de forma mais produtiva seu projeto de dizer.

A concepção de subjetividade, nesses trabalhos, tem um caráter de agentividade. Um sujeito "ativo" (não necessariamente e nem sempre consciente) seria o previsto nessas atividades de escrita - no entanto, a escolarização do texto levaria a procedimentos de supressão desse processo de agentividade. Vislumbrase, nesses trabalhos, a proposta de construção de uma escola que devolveria aos sujeitos a palavra, desenvolveria o processo de autoria e interlocução nas práticas de escrita. Neles, a relação entre sujeito e texto está necessariamente marcada. 
Em trabalhos de viés bakhtiniano, se poderia dizer que o caráter ativo do sujeito nas atividades de linguagem se manifesta na sua forma de diálogo com o discurso do outro. Dessa maneira, a noção de sujeito não se sustenta somente no seu aspecto cognitivo ou psicológico, mas é construída de forma responsiva no contexto sócio-cultural e histórico. Os trabalhos de Geraldi (1991; 1996) já apontavam, no Brasil, para essa perspectiva, em que tanto as atividades de leitura/ escuta quanto de escrita/oralização podem ser entendidas como processos em que se dá a constituição do sujeito nas práticas de linguagem - "Leitura e escritura, formas de interação entre os homens, é espaço ampliado de constituição." (GERALDI, 1996, p. 132, itálico adicionado). São atividades em que o sujeito dá respostas ativas, contrapalavras ao discurso do outro/Outro. Assim, o autor assume que o sujeito se constitui na e pela linguagem, nos processos interativos de que participa como coprodutor - "Escritura e leitura são sempre co-produção materializadas na sequência textual." (GERALDI, 1996, p. 132)

Ainda no campo dos estudos discursivos, no Brasil, nas décadas de 1980, 1990 e 2000, a relação do sujeito com o texto em atividades de escrita aparece em trabalhos sobre a noção de autoria e a de indícios de autoria. Em Mendonça (2016), analiso como essas noções, desenvolvidas no país por analistas do discurso, são atualizadas em documentos oficiais e em discursos que circulam na mídia. Retomo aqui algumas considerações presentes nesse trabalho.

Um filósofo que é base para muitos trabalhos sobre essa temática é Foucault. O princípio de autoria, segundo ele, é um dos mecanismos sócio-históricos de organização e ordenação do discurso; é concebido como "princípio de agrupamento do discurso, como unidade e origem das suas significações, como foco de sua coerência" (FOUCAULT, 2001 [1970], p. 26). Para Foucault (1992 [1969]), autor não é sinônimo de falante ou signatário e essa função discursiva se aplica a domínios como a literatura, a filosofia e a ciência, em que a autoria relaciona-se a uma "obra".

Orlandi (1988), na perspectiva da análise do discurso francesa e com base em escritos de Pêcheux, Foucault e Ducrot, propõe uma abordagem da autoria que amplia a proposta de Foucault: "Para Foucault o princípio da autoria não vale para qualquer discurso nem de forma constante. $\mathrm{O}$ modo como o estamos utilizando aqui difere deste autor. Para nós, o princípio é geral. $\mathrm{O}$ texto pode não ter um autor específico, mas sempre se imputa uma autoria a ele." (ORLANDI, 1988, p. 77).

Considerando a função autor ao lado das de locutor e enunciador - tal como propostas por Ducrot -, Orlandi entende-a como a que está mais próxima da "exterioridade", a que exige do sujeito maior responsabilidade pelo dizer e compromisso com as instituições em que se insere o discurso. $\mathrm{Na}$ instituição 
escolar, essa função constitui o espaço de o sujeito enunciar o que historicamente se espera dele. Conforme a autora, a injunção a um modo de dizer padronizado se manifestaria nessa função:

Assim, do autor se exige: coerência; respeito aos padrões estabelecidos, tanto quanto à forma do discurso como às formas gramaticais; explicitação; clareza; conhecimento das regras textuais; originalidade; relevância e, entre várias coisas, "unidade", "não contradição", "progressão" e "duração" do seu discurso. (ORLANDI, 1988, p. 78)

Possenti (2002), por sua vez, propõe que se considerem nos textos os indícios de autoria, perceptíveis no trabalho do sujeito sobre o interdiscurso, indícios que podem ser observados, por exemplo, na tomada de posição e na relação do sujeito com outros enunciados: "Pode-se dizer provavelmente que alguém se torna autor quando assume (sabendo ou não) fundamentalmente duas atitudes: dar voz a outros enunciadores e manter distância em relação ao próprio texto." (POSSENTI, 2002, p. 113). Em publicação posterior, Possenti (2013) reafirma o que entende por indícios de autoria, que não é, para ele, sinônimo de autoria (deixa claro que entende que um texto escolar pode ter indícios de autoria, mas não tem autor, considerando que autor deveria pressupor, aderindo à tese de Foucault, a presença de uma obra).

Em artigo anterior, acerca do estilo em textos escolares, Possenti (1993) já propunha que o diálogo que o sujeito desenvolve com outros textos/discursos é indício de singularidade em produções escolares, aproximando-se da posição que defenderá na década seguinte sobre os indícios de autoria em textos escolares:

Qual é o "gênero" de estilo mais possível? É o do aluno que se torna autor [...] no confronto de vários discursos, na elaboração de textos que permitem a presença nele de várias vozes. Trabalhar, nesse caso, é [...] operar na organização dos discursos que circulam. Textos polifônicos, eis a receita que sugiro a quem sonha com alunos que mantenham sua individualidade. Aluno sujeito de seu texto é o que pesa os vários discursos, que trabalha sobre os resultados históricos e continua fazendo história, fazendo sua história de relação com a linguagem. [...] (POSSENTI, 1993, p. 204)

Resta frisar que, na perspectiva dos autores em questão, autoria não é sinônimo de criatividade, tal como se entende esse termo em seu senso comum. É importante também destacar que tanto a autoria em Orlandi quanto os indícios de autoria em Possenti são manifestações discursivas da presença da subjetividade e intersubjetividade nos textos, já que deixam entrever, na textualidade, os movimentos do sujeito em relação com o outro/Outro.

Enfim, é preciso dizer que não discutirei neste artigo as (grandes) diferenças com que as diversas perspectivas aqui abordadas (Psicolinguística, Linguística do Texto, Nova Retórica, Análise do Discurso Francesa, Estudos Bakhtinianos, 
Aquisição da Escrita, Novos Estudos do Letramento, entre outras) concebem a noção de sujeito - a opção traçada no recorte que faço é destacar que uma noção de sujeito está presente e é relevante para a textualidade nesses discursos produzidos no interior dos estudos linguísticos (incluindo-se aí os estudos aplicados).

Nos estudos dos letramentos (e alfabetização), essa relação entre sujeito e texto também é evidenciada e reforçada desde os primeiros trabalhos desenvolvidos no Brasil. Neles, encontra-se um sujeito ativo e a escrita é pensada em uma perspectiva que coloca o linguístico em relação com o psicológico, o social, o cultural, o político - assim, os estudos sobre o processo de escrita envolvem os sujeitos que a produzem, tomados preferencialmente em uma abordagem interdisciplinar.

Parte dos trabalhos que se debruçam sobre a temática dos letramentos no Brasil, na década de 1980, dedicam-se ao estudo da aprendizagem da leitura e da escrita quando do processo de alfabetização. Destaco aqui obra de Kato (1995 [1985]), cuja primeira edição é de 1985, desenvolvida na perspectiva da Psicolinguística e que reúne artigos escritos entre 1980 e 1984. Apesar da delimitação de sua pesquisa nessa subárea, a autora aponta a necessidade de abordagem do tema da aprendizagem da leitura e da escrita de forma interdisciplinar, com participação, por exemplo, da sociolinguística, da linguística textual, das ciências da cognição, da antropologia e da fonoaudiologia. Kato, na obra em questão, discute métodos de alfabetização e chega à conclusão de que "muito do insucesso escolar poderia ser evitado se, em lugar da obsessão pelo "método", a escola procurasse ser um verdadeiro laboratório de observação do que ocorre no processo de aprendizagem, abordando a criança como um sujeito ativo desse processo" (KATO, 1995 [1985], p. 19-20, itálico adicionado).

Soares é outra autora brasileira que tem sido considerada uma das precursoras dos estudos sobre letramentos no país. Em comentário que faz de alguns de seus escritos, avalia que um artigo seu publicado em $1985^{\prime \prime}[\ldots]$ talvez mantenha interesse [...] por anunciar, sem ainda nomeá-lo, o conceito de alfabetismo ou letramento que se firmaria posteriormente". (SOARES, 2015, p. 14) Nesse estudo da década de 1980, Soares também chama atenção para a interdisciplinaridade e complexidade da noção de alfabetização - "[...] um conjunto de babilidades, o que a caracteriza como um fenômeno de natureza complexa, multifacetado" (SOARES, 1985, p. 21). Cite-se ainda outro fragmento:

[...] à natureza do processo de alfabetização, com suas facetas psicológica, psicolinguística, sociolinguística e linguística, é preciso acrescentar os fatores sociais, econômicos, culturais e políticos que o condicionam. Uma teoria coerente da alfabetização só será possível se a articulação e integração das várias facetas do processo forem contextualizadas social e 
culturalmente e iluminadas por uma postura política que resgate seu verdadeiro significado. (SOARES, 1985, p. 23)

A autora entende que este seu trabalho já se aproxima do que Street, em publicação contemporânea desse artigo, denomina de letramento ideológico. $\mathrm{O}$ autor, em artigo posterior (STREET, 2003), inclui seu trabalho no interior dos Novos Estudos do Letramento, perspectiva que enfoca os letramentos como práticas sociais múltiplas, que variam no tempo e espaço, e que se inserem em relações de poder. Define, no interior desses estudos, a noção de "letramento ideológico", em oposição ao "modelo autônomo ou neutro de letramento".

Colocando-se em perspectiva próxima à de Street, Soares (1985) já aponta para uma visão da escrita como atividade situada, social e culturalmente constituída; aponta também para um projeto político de educação inclusivo e democrático, que é recorrente em várias publicações e propostas de ensino/aprendizagem de seus pares no Brasil, entre eles os já citados neste artigo.

A questão da postura política em relação ao significado da alfabetização afeta, evidentemente, o processo de aprender a ler e a escrever. A diferença entre uma postura pretensamente "neutra" e uma explícita postura política fica clara quando se compara o trabalho em alfabetização desenvolvido, geralmente, nas escolas, com um trabalho na linha de Paulo Freire, para quem a alfabetização é um processo de conscientização e uma forma de ação política. (SOARES, 1985 , p. 23)

Até a década de 1980, não havia ainda se estabilizado um termo em português para se traduzir o termo inglês "literacy", presente nos estudos em língua inglesa sobre "escrita" - por exemplo, Ong (1982). O conceito não equivale a "alfabetização"; tal como aparece nesses estudos em inglês, é mais amplo (ultrapassam o escopo da Linguística, sendo objeto de reflexão em outros campos das Ciências Humanas). Em artigo posterior, Soares propõe que se traduza a noção por "alfabetismo", entendido como "um conceito complexo, pois engloba um amplo leque de conhecimentos, habilidades, técnicas, valores, usos sociais, funções, e varia histórica e espacialmente" (SOARES, 1995, p. 7).

Soares (1995) defende que o alfabetismo tem duas dimensões, a individual e a social.

A primeira, segundo a autora, é difícil de conceituar porque envolve um grande número de habilidades e conhecimentos em dois processos distintos linguística e psicologicamente, ler e escrever. Esses processos são entendidos, dadas essa complexidade, como um continuum. Na segunda dimensão, a social, o alfabetismo é concebido, de acordo com a autora, como prática social situada. Assumindo o risco de simplificar as tendências desses estudos sobre a escrita numa perspectiva social, 
agrupa-as em duas tendências: uma versão "fraca", considerada progressista/"liberal"; outra versão "forte" tida como radical/"revolucionária" (destaques da autora). A tendência chamada de progressista praticaria um "alfabetismo funcional" de adaptação dos indivíduos às demandas do dia-a-dia da convivência nas sociedades, assim o alfabetismo se tornaria "[...] responsável pelo desenvolvimento cognitivo e econômico, pela mobilidade social, pelo progresso profissional, pela promoção da cidadania" (SOARES, 1995, p. 35). Já na outra tendência, nas palavras da autora,

[...] as habilidades de leitura e escrita [...] são vistas como um conjunto de práticas socialmente construídas envolvendo o ler e o escrever, configuradas por processos sociais mais amplos, e responsáveis por reforçar ou questionar valores, tradições, padrões de poder presentes no contexto social. (SOARES, 1995, p. 35)

A autora, no artigo em questão, após argumentar a favor da complexidade do fenômeno do alfabetismo, aponta seu aspecto interdisciplinar - defendo aqui que esse caráter interdisciplinar dos estudos dos letramentos reforça a tendência de se estudar/conceber o texto escrito em seu processo de constituição e em relação com seus usuários e seu contexto de produção.

Também uma publicação organizada por Kleiman (1995) destaca o aspecto interdisciplinar dos estudos dos letramentos e se insere na tendência dos Novos Estudos dos Letramentos. A obra inclui trabalhos em diferentes perspectivas e que são divididos pela organizadora em grupos temáticos que enfocam "relações entre oralidade e escrita", "relações do sujeito não-escolarizado na sociedade brasileira" e "a ideologia do letramento na mídia e seus reflexos na constituição da identidade do não-escolarizado" - essa divisão, além de indiciar as linhas de trabalhos desenvolvidos nos estudos de letramentos à época, também aponta para a preocupação com o sujeito (em especial o não-escolarizado, às margens dos sistemas dominantes instituídos) nesses estudos. Assim, a despeito dos diferentes enfoques teórico-metodológicos, segundo Kleiman (1995, p. 11) a obra tem uma unidade que remete à identidade social:

[...] os estudos sobre o letramento que aqui incluímos têm um traço em comum: o letramento é aqui considerado enquanto conjunto de práticas sociais, cujos modos específicos de funcionamento têm implicações importantes para as formas pelas quais os sujeitos envolvidos nessas práticas constroem relações de identidade e de poder.

Dessa maneira, pode-se dizer que a coletânea se insere na perspectiva que Street chama de modelo ideológico. Kleiman $(1995$, p. 8) destaca essa abordagem na publicação que organiza: "A palavra de ordem nos estudos sobre o letramento que 
se voltam para a transformação da ordem social é "empowerment through literacy", ou seja, potencializar através do letramento".

O trabalho de Street foi fundamental para o desenvolvimento das pesquisas brasileiras nesse campo. Publicação datada de 1994 e traduzida para uma revista brasileira em $2006^{2}$ indicia a centralidade do sujeito nesses estudos. Vejamos a seguir, nos trechos colocados em itálico, como essa questão é atualizada em seu trabalho:

[...] as práticas de letramento são constitutivas da identidade e da pessoalidade (personhood). O que quero dizer com isso é que, quaisquer que sejam as formas de leitura e escrita que aprendemos e usamos, elas são associadas a determinadas identidades e expectativas sociais acerca de modelos de comportamento e papéis a desempenhar. [...] existe frequientemente uma relação fundamental entre os campos ideológicos de pessoalidade e letramento. O que vem a ser uma pessoa, a ser moral e a ser humano em contextos culturais específicos é muitas vezes representado pelo tipo de práticas de letramento em que a pessoa está comprometida. (STREET, 2006 [1994], p. 466/469)

Não somente a noção de subjetividade se apresenta nesse artigo, mas também a de intersubjetividade, que é atualizada como processo de "negociação" do sujeito quando das práticas de letramento, a qual é constitutiva da identidade do sujeito:

[...] também gostaria de considerar de que modo os letramentos podem ser lugares de negociação e de transformação. [...] Recentemente, essa perspectiva [determinista] foi substituída por outra que dá maior reconhecimento ao agenciamento* (agency), ao modo como as pessoas em diferentes posições rejeitam e negociam as posições que aparentemente lhe são atribuídas. (STREET, 2006 [1994], p. 471)

Dessa forma, os estudos dos letramentos nessa perspectiva dos Novos Estudos dos Letramentos distanciam-se de trabalhos focados nas diferenças linguísticas entre oralidade e escrita e no acesso à escrita como um caminho para inserção social, no sentido passivo dessa inserção. Trata-se de "apoderar-se" do discurso do outro e "empoderar-se", no sentido de luta e construção social:

[...] Kulick e Stroud [...] querem demonstrar "como os indivíduos numa sociedade recémletrada, longe de serem passivamente transformados pelo letramento, em vez disso aplicam ativa e criativamente as habilidades de letramento para atender a seus próprios propósitos e necessidades"; como eles "se apoderam" do letramento [...] os "sujeitos" não são "tábuas rasas" como tantas campanhas de desenvolvimento da alfabetização parecem supor (Street, 1987). (STREET, 2006, [1994] p. 457)

Esta publicação, em perspectiva etnográfica e cujo original é da década de 1990, encontra ecos em trabalhos recentes também nas análises de discurso.

2. O artigo foi inicialmente publicado em VERHOEVEN, Ludo (Ed.). (1994). Functional Literacy: theoretical issues and educational implications; Amsterdam/Philadelphia, John Benjamins, p. 95111. 
Cassany e Castellà (2010), por exemplo, assumem uma perspectiva crítica nas práticas de letramento (o sujeito nessa perspectiva é ativo no sentido de "agente", "com posicionamento", "não ingênuo", "atuante"). Veja-se também, no Brasil, Komesu e Galli (2016), que, em estudo sobre autoria nos letramentos digitais, entendem que a relação do "sujeito de discurso" com os letramentos digitais seja de "empoderamento", considerando trabalhos no interior dos Novos Estudos do Letramento e as formas de resistência ao poder estudadas por Foucault.

Também na década de 1990, ainda é preciso destacar estudos sobre multiletramentos, que serão importantes para o ensino/aprendizagem de produção textual no Brasil, tendo em vista as novas relações de letramento com as mídias digitais, em que se misturam diferentes linguagens e gêneros do discurso, e a grande diversidade cultural que elas colocam em evidência. $\mathrm{O}$ artigo-manifesto produzido por The New London Group (1996), um conjunto de autores em pesquisa colaborativa, busca alternativas pedagógicas de letramento nesse novo cenário semiótico, cultural e político. Os autores propõem o conceito de "Design" para definir o movimento do sujeito-estudante sobre os produtos culturais já dados na construção de uma nova realidade que esteja adequada para seus projetos de vida, na construção de um futuro em que as diferenças tenham visibilidade e poder. Os designs "disponíveis", já dados, incluem modos de dizer e de fazer na "ordem do discurso" de uma determinada sociedade, num momento histórico específico - esses modos de dizer e de fazer relacionam-se aos gêneros, estando diretamente relacionados à interação verbal e aos sujeitos envolvidos na interação. Esses designs disponíveis são "rearranjados", quando da "atividade semiótica" (interpretação/ produção) conforme a história individual de cada grupo social, nunca sendo simplesmente reproduzidos. Essa "nova" realidade atingida é, para os autores, sempre provisória. Além disso, ela inclui uma nova identidade para os sujeitos envolvidos, que reconstroem e renegociam sua identidade no processo do "Design". Trata-se de "sujeitos críticos", "criativos" e "responsáveis" na construção desse futuro coletivo e multicultural. Neste caso, também o sujeito é "ativo" - "active designers of meaning" / "designers of social futures" - ao manipular (interpretar e produzir) bens culturais em diferentes linguagens (verbal, visual, auditiva, gestual, "espacial", multimodal).

Essa proposta pedagógica dialoga fortemente com as desenvolvidas recentemente no Brasil, não somente na valorização do aspecto crítico do posicionamento do sujeito e no enfoque das diversidades sócio-culturais e étnicas, mas também no destaque do trabalho com multiletramentos e multimodalidade, aliado à abordagem dos gêneros textuais ou discursivos. Rojo (2005), em 
levantamento de pesquisas sobre os gêneros textuais e discursivos em uma instituição brasileira, na área da Linguística Aplicada, entende que o fato de os gêneros serem tomados como objeto de ensino ou suporte para atividades de leitura e escrita nos Parâmetros Curriculares Nacionais na década de 1990 leva a uma "explosão" de pesquisas nessa temática na instituição em pauta a partir desse período. Considerando essa ampliação dos estudos dos gêneros no Brasil e sua relação com atividades de leitura e escrita na escola - ver, por exemplo, para a primeira situação, Meurer, Bonini, Motta-Roth (2005), e para a segunda, Rojo (2001), Brait (2000), Geraldi (2010) - o interesse aqui é: na próxima seção, destacar alguns aspectos de como a subjetividade e a intersubjetividade aparecem no discurso sobre a escrita em alguns documentos oficiais direcionados ao Ensino Médio, que influenciam direta ou indiretamente a produção de materiais didáticos; em seguida, discutir em que medida a subjetividade e a intersubjetividade aparecem em propostas de produção de textos numa coleção didática direcionada ao Ensino Médio aprovada no PNLD2018; por fim, relacionar os resultados da análise do corpus à problemática do ensino/ aprendizagem com enfoque nos gêneros.

\section{SUBJETIVIDADE E/OU INTERSUBJETIVIDADE E AS PRÁTICAS DE ESCRITA EM DOCUMENTOS OFICIAIS NO BRASIL.}

Discursos oficiais direcionados às políticas e práticas educacionais nacionais incorporaram parte dos estudos científicos citados sobre a escrita em contexto escolar. Os Parâmetros Curriculares Nacionais (PCN), a Base Nacional Comum Curricular (BNCC), o Guia do PNLD são exemplos de enunciados em que há essa incorporação.

Já nos PCN direcionados ao Ensino Fundamental I, de 1997, afirma-se, por exemplo, que "a razão de ser das propostas de uso da fala e da escrita é a interlocução efetiva, e não a produção de textos para serem objetos de correção (...)." (BRASIL, 1997, p. 19) Todos os volumes dos PCN reafirmam a ideia de a linguagem ser atividade interlocutiva, ou seja, a linguagem ser espaço de realização de um projeto de dizer de um eu para um outro, ser espaço de manifestação/constituição de subjetividade e de intersubjetividade. Nos documentos direcionados ao Ensino Médio $(\mathrm{PCN}+)$ encontra-se a seguinte passagem, em que esse projeto de dizer aparece como "intencionalidade dos produtores":

Tais conceitos [interlocução, significação, dialogismo] perpassam quase todas as atividades da disciplina [Língua Portuguesa]. Compete, porém, ao professor de Língua Portuguesa propor situações que incentivem a produção de textos orais e escritos nas quais se considerem: 
- um público ouvinte ou um leitor específico;

- a situação de produção em que se encontram os interlocutores;

- as intencionalidades dos produtores.

O que se propõe é que as aulas de redação operem com esses conceitos, para que a atividade adquira significado para o aluno. (BRASIL, 2000b, p. 61)

Mais adiante, destaca-se a necessidade de, nas atividades de produção textual, os alunos terem percepção clara acerca de

- o que tem a dizer sobre o tema proposto, de acordo com suas intencionalidades;

- o lugar social de que ele fala;

- para quem seu texto se dirige;

- de quais mecanismos composicionais lançará mão;

- de que forma esse texto se tornará público. (BRASIL, 2000b, p. 80)

Nesse caso, ter um projeto de dizer não se limita a ter "o que dizer" ou a uma intencionalidade, mas engloba o processo de produção, relacionado a imagens do lugar de onde se enuncia, imagens do interlocutor a quem se dirige, estratégias de organização do dizer e de sua publicização.

Em atividades de uso de linguagens, o $\mathrm{PCN}+$ propõe que se desenvolva o protagonismo do estudante, que aparece relacionado a situações em que o aluno se torna "sujeito de sua própria aprendizagem", situações que envolvem a sua autonomia. Assim, apesar de o protagonismo fazer parte da relação do sujeito com o conhecimento e, nas aulas de Língua Portuguesa, ser desejável em todas atividades que envolvem a relação com a linguagem, o documento dá como exemplos somente duas situações de escrita em que esse protagonismo pode ser ativado: texto opinativo que aborde situação-problema e proposta de intervenção social; relato pessoal.

\section{Protagonismo}

Não se pode tomar o aluno como um receptor passivo dos conhecimentos ministrados pelo professor. $\mathrm{Na}$ interação que estabelece com o assunto, o professor e os colegas, o aluno deve tornar-se sujeito da própria aprendizagem, revelando autonomia para lidar com a construção do conhecimento.

Algumas situações que ativam o protagonismo:

- na produção de um texto opinativo que aborde uma situação-problema, é desejável que o aluno elabore propostas articuladas e pertinentes à sua visão da questão, bem como argumentos que sustentem seu ponto de vista (competência $V$ do Enem);

- na produção de um texto narrativo - como um relato, por exemplo - o aluno deve ser incentivado a colocar-se na situação de quem reconta um fato ocorrido com ele. (BRASIL, 2000b, p. 61)

Em outras passagens, o protagonismo, na disciplina de Língua Portuguesa, aparece relacionado também à leitura, ao confronto de opiniões e pontos de vista. Mas a ideia do protagonismo não é suficientemente desenvolvida nos PCN, 
ficando mais evidente o enfoque na textualidade como uma unidade de ensino e no gênero como um conteúdo de ensino, e menos na construção do projeto de dizer do autor do texto que é produzido. Inclusive, as noções de autoria ou indício de autoria, tal como aparecem nos estudos de analistas do discurso citados, não aparecem nos PCN como característica/qualidade dos textos.

Já o Guia do Participante da redação do Exame Nacional do Ensino Médio de 2013 (BRASIL, 2013), ao explicitar os critérios de atribuição de pontos na "Competência 3 - Selecionar, relacionar, organizar e interpretar informações, fatos, opiniões e argumentos em defesa de um ponto de vista", atualiza inadequadamente, em um novo tema relacionado ao contexto avaliativo, as posições de Orlandi e Possenti sobre autoria; veja-se o fragmento a seguir - esse critério se mantém na correção da redação do Enem de 2018, conforme aparece no Redação no Enem 2018 - Cartilba do Participante (BRASIL, 2018).

O quadro, a seguir, apresenta os seis níveis de desempenho que serão utilizados para avaliar a Competência 3 das redações do Enem 2013:

200 pontos - Apresenta informações, fatos e opiniões relacionados ao tema proposto, de forma consistente e organizada, configurando autoria, em defesa de um ponto de vista.

160 pontos - Apresenta informações, fatos e opiniões relacionados ao tema, de forma organizada, com indícios de autoria, em defesa de um ponto de vista. (BRASIL, 2013, p. 18-19)

A matriz de correção da prova de redação do Enem, como discutimos em Mendonça (2016), ressignifica o discurso dos analistas de discurso citados, aproximando conceitos diferentes e valorizando o que chama de "autoria", em detrimento dos "indícios de autoria", que são tomados no processo avaliativo como um nível inferior de "autoria", como "insuficientes". Neste artigo, não retomaremos a discussão feita em Mendonça (2016); interessa aqui destacar que, apesar de a questão da autoria não ser explorada nos PCN, ela é usada como critério na avaliação da redação da prova do Exame Nacional do Ensino Médio. Essa versão do Guia citada aqui, de 2013, já é parte de edição do Enem em seu novo formato (houve uma mudança na prova em 2009, adequando-a ao modelo de vestibulares) e, a partir de 2012, o exame já é utilizado como sistema de acesso ao ensino universitário na maioria das universidades federais do país. Essa abrangência e aplicabilidade da prova fazem desse modelo de avaliação de redação um parâmetro para a escrita em cursos preparatórios e outros segmentos educacionais brasileiros.

Mas foram os $\mathrm{PCN}$, como não poderia deixar de ser, que interferiram diretamente, pelo menos no começo da década de 2010, nos critérios utilizados para avaliação de material didático para o Ensino Médio feita pelo Plano Nacional dos Livros Didáticos. Assim, no Guia de livros didáticos: PNLD 2012 - Lingua Portuguesa 
(BRASIL, 2011), os critérios presentes na ficha de avaliação sugerida ao professor não contemplam a autoria e também não abrem espaço para a questão do projeto de dizer do autor/aluno na atividade escrita. As questões enfocadas são:

As atividades situam a prática da escrita em seu universo

de uso social? [...]

8.1 Trabalham com os diferentes letramentos (literário, midiático, de divulgação científica, jornalístico, multimodal etc.)?

8.2. Definem o contexto de produção do texto (esfera, suporte, gênero, destinatário)?

8.3. Definem objetivos plausíveis para a escrita do aluno?

8.4. Propõem temas pertinentes à faixa etária e à formação cultural do aluno?

9. As atividades contribuem efetivamente para o desenvolvimento da proficiência em escrita? [...]

9.1. Contemplam as diferentes etapas do processo de produção

(planejamento, escrita, revisão, reformulação)?

9.2. Fornecem subsídios para a elaboração temática (seleção e

articulação dos conteúdos)?

9.3. Orientam a construção da textualidade de acordo com o contexto de produção e o gênero proposto (recursos de coesão e coerência, seleção lexical, recursos morfossintáticos)?

9.4. Orientam o uso do registro de linguagem adequado ao gênero e à situação (formal, informal)?

9.5. Propõem referências e/ou exemplos dos gêneros e tipos de texto que pretendem ensinar o aluno a produzir? (BRASIL, 2011)

A ficha de avaliação do Guia de 2015 (BRASIL, 2014) permanece igual à de 2012 em relação aos itens sobre a produção de textos. Já o Guia de 2018 (BRASIL, 2017, p. 91-92) apresenta mais critérios de avaliação das atividades de produção textual em sua ficha; para o que nos interessa diretamente aqui, destacamos que: inclui, no item 8.2, a autoria ("Esclarecem o contexto de produção do texto (esfera social, suporte, gênero, destinatário e autoria)?") e inclui um novo item, 9.1: "Trabalham a relação entre prática de escrita e gênero, atentando para questões como discurso, ideologia, autoria, esfera de atividade, efeitos de sentido previstos ou não previstos?". Ao se incluir a autoria no contexto de produção do texto e ao se indagar sobre a relação entre prática de escrita e gênero, ampliando o escopo da escrita nos aspectos relativos aos efeitos de sentido previstos, à autoria e à ideologia, abre-se espaço para que o professor busque no material indícios/evidências, nas atividades propostas, da atuação do eu sobre o outro, de marcas que o eu deixa em seu texto de seu projeto de dizer nessa atividade Essas mudanças também revelam que o processo de avaliação dessa edição de 2018 do PNLD exigiu das coleções em análise esse enfoque nas atividades de produção textual, o que constitui um avanço em relação às edições anteriores. No entanto, como não está claro o que se entende, nesse guia, por autoria e, considerando a ambivalência que a noção possui 
em contexto escolar e avaliativo (como discutido anteriormente), o avanço ainda é tímido

Após os PCNEM e PCN+, ambos publicados em 2000, as diretrizes curriculares para o Ensino Médio no Brasil passaram por reformulação. Da Resolução No. 2, de 30 de janeiro de 2012 (BRASIL, 2012), destacamos: o Art. 21, que define para o Enem a função de "avaliação classificatória, que contribui para o acesso democrático à Educação Superior"; o Art. 16, que institui a valorização da leitura e da produção escrita em todos os campos do saber, a "utilização de diferentes mídias como processo de dinamização dos ambientes de aprendizagem e construção de novos saberes" e "produção de mídias nas escolas a partir da promoção de atividades que favoreçam as habilidades de leitura e análise do papel cultural, político e econômico dos meios de comunicação na sociedade"; a presença do "estudante protagonista" relacionado a atividades de autonomia no processo de pesquisa/investigação e a situações de participação e transformação social. Assim, interessa aqui destacar que a Resolução reforça a tendência de abrangência e processo classificatório que o Enem vinha assumindo desde a década anterior - o que pode ter interferido na concepção da produção de textos no Ensino Médio - e já adianta uma tendência que se confirmará na Base Nacional Curricular Comum (BNCC): o enfoque no trabalho com multiletramentos. Este documento, finalizado em 2017, apresenta diferenças importantes, comparado aos PCN, na proposta de trabalho com gêneros na escola - propõe-se a valorização de atividades de leitura/ escuta e escrita/oralização de gêneros multimodais e digitais, em diferentes suportes e linguagens. Como esse documento é posterior à publicação da coleção didática que é analisada neste artigo, não aprofundaremos a exposição de seu conteúdo, pois não é base para a produção didática em questão.

\section{CONSIDERAÇÕES SOBRE SUBJETIVIDADE/INTERSUBJETIVIDADE E GÊNEROS EM MATERIAL DIDÁTICO}

Considerando que o interesse deste artigo é refletir sobre a subjetividade/ intersubjetividade em propostas de produção de textos em livro didático direcionado ao Ensino Médio e sua relação com os gêneros, selecionamos como objeto de discussão a coleção didática Veredas da Palavra (ALVES; MARTIN, 2016a, 2016b, 2016c), composta por três volumes direcionados ao Ensino Médio. Os motivos que levaram a essa escolha são expostos a seguir.

A coleção foi aprovada pelo Plano Nacional do Livro Didático de 2018 ; portanto, tendo em vista que satisfaz aos critérios de avaliação propostos pelo PNLD, 
cabe uma discussão de como ela atualiza os discursos sobre a produção textual escolar levantados neste artigo. Além disso, também foi considerado que o material didático apresenta propostas de atividades com temáticas relacionadas à inclusão social e participação democrática na sociedade, o que seria espaço privilegiado para estímulo ao protagonismo na produção de textos, como se propõe nos PCN e na RESOLUÇÃO Nº 2, DE 30 DE JANEIRO 2012, documentos que são base curricular para a publicação didática em pauta. Outro aspecto que chama atenção na coleção é o rol amplo de gêneros nas atividades de produção textual, multimodais e que se constituem em diversas esferas de atividade - cartaz de divulgação, currículo, resenha, ensaio, artigo de opinião, notícia, reportagem, poema, crônica, conto, cena teatral, relatório de pesquisa escolar, seminário, dissertação escolar, blog, debate.

No entanto, o material didático, conforme resenha sobre a coleção no Guia do PNLD - 2018 - Ensino Médio, apresenta limitação em relação à "autonomia e à atuação do estudante em termos das práticas de linguagem. Assim, itens como [...] os relativos às condições de circulação do texto (como discurso, ideologia, e gênero textual/discursivo) ganham tratamento menos detalhado" (BRASIL, 1997, p. 48). Embora a obra situe as propostas de escrita em seu contexto social e situação mais imediata de comunicação, a resenha destaca que

(...) os elementos da situação de interação, tais como autoria, interlocutor previsto e função social do gênero são pouco considerados. $\mathrm{O}$ interlocutor efetivo dos textos produzidos poderia ter um espectro mais amplo, uma vez que a coleção enfoca, prioritariamente, os próprios estudantes como interlocutores. (...) (BRASIL, 1997, p. 50)

Como as limitações destacadas pela resenha dizem respeito às questões que nos interessam investigar, essa coleção foi selecionada para análise. As questões de pesquisa foram: em que medida a autoria, o interlocutor previsto, as formas de circulação do gênero, o protagonismo são considerados? A subjetividade/ intersubjetividade nas propostas de escrita relaciona-se com a forma como o material lida com os gêneros?

Os livros se dividem em unidades, constituídas por capítulos, sendo o último dedicado à produção de textos, que se apresenta como um "fechamento" de cada unidade. Então, o movimento proposto, no trabalho com a linguagem, é no sentido da leitura para a escrita, sendo que a análise linguística é tratada, em média, em um capítulo de cada unidade. As autoras, na apresentação do material, destacam que um dos principais objetivos da obra é "fornecer subsídios para a melhor compreensão dos textos, especialmente os literários", acrescentando ser a literatura "capaz de realizar mudanças notáveis, fazendo de nós sujeitos mais sensíveis, éticos e criativos" (ALVES; MARTIN, 2016a) Veja-se que as autoras entendem que a leitura 
tem relação direta com a formação do sujeito "sensível, ético, criativo", entretanto não citam o papel da produção de textos nessa formação. De forma geral, pode-se dizer que a coletânea explora mais as atividades de leitura, reservando à escrita e à produção oral um espaço delimitado e limitado - não se priorizam atividades, por exemplo, de retextualização, de discussão oral e escrita a partir de textos propostos para estudo e leitura, sendo que as produções textuais estão restritas a um capítulo delimitado, dedicado ao estudo/interpretação de um gênero textual, e a atividade escrita se coloca como exercício do gênero em questão. Assim, essas propostas de escrita, na contramão de discussões recentes sobre letramentos nos estudos da Linguística e da Linguística Aplicada, não possuem um conjunto de textos cuja temática serve de base para a escrita, de forma a se integrarem efetivamente atividades de leitura e escrita considerando a construção, a partir de um conjunto de discursos heterogêneos, de um ponto de vista, de um projeto de dizer.

Considerando o conjunto de produções textuais dos volumes da coleção, suas estabilidades, e também os objetivos deste trabalho, agrupamos a discussão em quatro blocos: inicialmente, fazemos uma reflexão sobre a temática da autoria na coleção; em seguida, apresentamos a ressignificação da noção de protagonismo tal como aparece no material em análise; enfim, discutimos a questão mais ampla da subjetividade/intersubjetividade no conjunto das propostas de produção escrita e comentários direcionados aos professores - essa discussão, por sua vez, é dividida em duas partes, sendo a primeira destinada à reflexão sobre o trabalho que se propõe na construção do destinatário dos textos a serem redigidos, e a última destinada ao trabalho com a construção de um projeto de dizer nos textos e sua relação com o trabalho com gêneros proposto no material.

\subsection{A noção de autoria ou indícios de autoria na coleção didática}

\section{Como citado anteriormente, o Guia do PNLD - 2018 - Ensino Médio} possui, entre os critérios para avaliação dos livros didáticos presentes na Ficha de Avaliação, a noção de "autoria", integrada ao "contexto de produção do texto", situação em que aparece junto com as categorias "esfera social", "suporte", "gênero" e "destinatário". A noção de autoria também aparece na Ficha de Avaliação, inserida naquilo que os avaliadores chamam de "relação entre prática de escrita e gênero" - nesse caso, além de "autoria", encontram-se "discurso", "ideologia", "esfera de atividade", efeitos de sentido previstos e não previstos. Como autoria não estava na Ficha de Avaliação das edições anteriores do PNLD, entende-se que a noção não fique em evidência nas atividades de produção textual na coleção em pauta. Aliás, a noção, relacionada à atividade de escrita, praticamente não é citada ao longo dos 3 
volumes, nem no Manual do Professor que acompanha cada um dos volumes (uma exceção será comentada no item 3.3 deste artigo). Também não aparecem indícios de autoria.

Entendemos como surpreendente essa "quase ausência", considerando-se a ampla bibliografia produzida nos estudos do discurso relativa ao tema, em especial relacionando-a ao texto produzido em contexto escolar - neste artigo, citamos alguns desses trabalhos (ORLANDI, 1988; POSSENTI, 2002). Resta ainda mencionar que a autoria (ou indícios de autoria, ou até marcas de autoria) é explorada em exames vestibulares importantes no país, nos itens considerados desejáveis em produções textuais escritas - alguns desses vestibulares são o da Unicamp, da UFSC, da UFU, da UERJ. Em especial, como se trata de noções que foram incorporadas pelo Enem, na avaliação da competência 3 (conforme já citado neste artigo), uma discussão sobre sua pertinência ou importância em práticas de escrita seria imprescindível para, principalmente, alunos que finalizam o Ensino Médio.

Na coletânea em questão, há um capítulo em que a dissertação escolar é tomada como gênero textual. Nesse capítulo, as autoras propõem um trabalho de discussão de textos bem avaliados na prova da FUVEST (o que entendemos como positivo para a formação daquele aluno que pode vir a fazer exames vestibulares), mas não abordam em detalhes, no livro direcionado aos alunos, os critérios de correção utilizados em provas de vestibulares nem no Enem, em que há, além de aspectos da textualidade já trabalhados ao longo da coleção, a questão da autoria e indícios de autoria. Os níveis de desempenho considerados para avaliar as competências na prova do Enem aparecem somente para o professor, sem orientações específicas, no Manual do Professor no capítulo relativo à dissertação escolar.

A temática da autoria, ou indícios de autoria, quando apropriada por instrumentos de avaliação na esfera didático-pedagógica, ganha um novo tema, ora ligado ao velho discurso da criatividade, ora ligado à valoração em níveis típica dos processos avaliativos (MENDONÇA, 2016). Em meio a essa ambivalência, sua presença em propostas de produção de textos em materiais didáticos não necessariamente levaria a uma melhora na qualidade dos textos, ou à produção de textos em que a subjetividade/intersubjetividade estaria marcada, já que autoria tem sido conceito que, tomado por óbvio, não se explicita nem se define.

\subsection{Protagonismo em atividades de produção textual}

Como já exposto anteriormente, o protagonismo do estudante seria uma meta a se alcançar em atividades de ensino, conforme os $\mathrm{PCN}+$, documento em que essa qualidade aparece relacionada a ser "sujeito de sua própria aprendizagem", possuir 
"autonomia para lidar com a construção do conhecimento", ser capaz de elaborar "propostas articuladas e pertinentes à sua visão da questão, bem como argumentos que sustentem seu ponto de vista (competência V do Enem)" (BRASIL, 2000b, p. 61), estando também relacionada à leitura e ao posicionamento em um confronto de pontos de vista e a situações de participação e transformação social.

$\mathrm{Na}$ coleção didática em análise, essa noção aparece pouco. Uma situação em que é utilizada é no Volume 3, no capítulo dedicado ao estudo da dissertação escolar, exatamente quando as autoras comentam a especificidade da prova do Enem de exigir que sejam elaboradas propostas de intervenção social para o problema apresentado, as quais são avaliadas na competência 5 da matriz do Enem. As autoras afirmam, sobre essa prova, que "os temas se ocupam de questões relativas ao protagonismo juvenil (a participação ativa dos jovens como cidadãos), à sociedade brasileira e à cidadania." (ALVES; MARTIN, 2016c, p. 356, itálico adicionado)

No Volume 1 a noção também é atualizada, neste caso relacionada a duas propostas de produção textual: um cartaz de divulgação e um de campanha de divulgação (ALVES; MARTIN, 2016a, p. 79-80). A noção do sujeito protagonista vem expressa no comentário das autoras, nas margens das propostas, em azul, dirigindo-se ao professor:

Incentive os alunos a discutir amplamente questões relativas ao ambiente escolar, à convivência nele e às formas de melhorá-lo. Leve-os a perceber que podem atuar em benefício da comunidade escolar em que estão inseridos e que, desse modo, sendo proativos, podem ser protagonistas da própria história. (ALVES, MARTIN, 2016a, p. 79, itálico adicionado)

Perceba-se que essa atitude de protagonismo não está relacionada, na instrução dada pelas autoras, diretamente à atividade de escrita, mas a uma ação social tomada como independente do uso da linguagem.

Em outra situação, no Volume 2 da coleção, também se atualiza a noção de protagonismo, com novo tema, ligado a questões relativas à identidade de comunidades. No livro direcionado ao aluno, encontra-se a seguinte questão sobre textos lidos acerca de comunidades indígenas e empoderamento social: "Você acredita que projetos como o desenvolvido pelos Xucuru são válidos para registrar a memória, fortalecer a identidade e dar visibilidade aos povos indígenas? Você conhece outras iniciativas de protagonismo social em sua comunidade? Discuta esse assunto com os colegas" (ALVES, MARTIN, 2016b, p. 109, itálico adicionado). No Manual do Professor, incentiva-se que o professor amplie essa discussão e desenvolva o protagonismo dos estudantes a partir de atividade de "pesquisas e visita a centros comunitários" (ALVES, MARTIN, 2016b, p. 386), o que inclui, evidentemente, utilização de atividades de linguagem nesse desenvolvimento. No entanto esse 
trabalho que relaciona protagonismo social e letramentos é pouco explorado na coleção.

Enfim, o protagonismo poderia, como a autoria, ser uma das dimensões da subjetividade/intersubjetividade a ser mobilizada em atividades de letramentos em contexto didático-pedagógico. No entanto, é preciso que o conceito seja ampliado para que seu escopo inclua atividades de uso da linguagem. Um exemplo de atividade interessante, no material didático em análise, será discutido a seguir, quando da produção de um blog - nessa proposta, encontram-se relacionadas, no material, as noções de autoria e protagonismo.

\subsection{A construção do interlocutor e do projeto de dizer do autor: uma reflexão sobre os gêneros em material didático}

De forma geral, a resenha presente no Guia do PNLD faz justiça quando avalia a coleção no tratamento dado aos elementos de situação comunicativa e contexto de produção nas atividades de produção textual. Assim, apesar de a obra situar as propostas de escrita, o aspecto da autoria não recebe um tratamento adequado, como argumentamos aqui, e a construção do interlocutor previsto está ainda presa a um modelo "artificial" de uso do texto, já que os interlocutores, como afirma a resenha, são, em grande parte das propostas, os próprios estudantes. Destaco aqui uma atividade que avança em relação à questão da artificialidade do texto nas atividades escolares e outra que indicia as dificuldades encontradas pelas autoras da coleção no movimento de situar as atividades de escrita: a primeira se trata da produção de um blog, a segunda, de um conto.

O volume direcionado ao primeiro ano do Ensino Médio tem como última atividade de escrita a produção de um blog. Inicialmente, as autoras expõem as características do blog, e instruem, passo a passo, de forma clara e detalhada, a sua forma de criação. A seguir, apresentam duas propostas de produção, as quais se deve escolher a realização de uma. Uma delas é individual e outra é coletiva. Transcrevemos, a seguir, a produção de blog individual.

\footnotetext{
Você deve selecionar um tema de seu interesse, criar o seu blog e colocá-lo para funcionar. Escreva e poste, por exemplo, textos sobre temas de seu interesse, como esportes, cinema, música, leituras, viagens, acontecimentos de âmbito local ou de abrangência maior.

Por se tratar de um projeto escolar, é importante definir, de antemão, a linguagem, o vocabulário e a abordagem que os temas receberão.

A turma pode definir o tempo em que os blogs ficarão no ar para navegação de todos e marcar uma data para avaliá-los posteriormente. (ALVES, MARTIN, 2016a, p. 341).
} 
Há, na proposta, a instrução para a linguagem "adequada" a ser utilizada no blog, bem como para a adequação da abordagem temática, tendo em vista o fato de se tratar de um projeto escolar - no Manual do Professor, as autoras alertam para o uso de linguagem de baixo calão, tanto nos posts quanto em comentários. Assim, apesar desse aspecto da "escolarização" da atividade - que é inevitável, já que se trata mesmo de projeto escolar, situado como atividade proposta por um educador -, ela apresenta-se muito próxima das práticas de escrita efetivas, pois o aluno deve lidar com o uso da linguagem em seu gênero e suporte específico - computador -, selecionar temáticas de seu interesse, layout, gerenciar comentários e postar por sua vez, comentários nos blogs dos colegas. A proposta de criação de blog coletivo também abre para essas atividades.

Na seção que se segue às propostas, Roteiro de Avaliação (que se apresenta sistematicamente na coleção, após a apresentação das propostas de atividade escrita, e se dirige aos alunos), há um conjunto de questões "que devem ser levadas em conta na hora de avaliar a produção":

1. Os participantes do blog exploraram com adequação e criatividade o tema proposto?

2. A linguagem e o vocabulário foram adequados?

3. Houve participação contínua no blog ou muitos participaram no início da experiência e depois o projeto foi esquecido?

4. O blog contribuiu para enriquecer discussões sobre o(s) tema(s) proposto(s) em sala de aula ou sua contribuição foi apenas na mídia virtual?

5. Todos conseguiram dominar as ferramentas para a criação de um blog, ou ainda há quem tenha dúvidas? Como resolver esse problema? (ALVES, MARTIN, 2016a, p. 342).

Dessa forma, essas propostas de escrita exploram tanto a construção de um projeto de dizer sobre o tema (na escolha de um tema), quanto a construção de estratégias para produzir efeitos específicos nos interlocutores a quem se dirige efetivamente - o que está relacionado à construção de possibilidade de emergência de indícios de autoria, tal como propõe Possenti (2002), em que o sujeito trabalha com os "discursos dos outros" e marca neles sua singularidade, na relação com esses "outros". No Manual do Professor, as autoras explicitam que entendem que criar o próprio blog se constitui em "exercício de autoria", bem como destacam que o blog é "um gênero que propicia trocas, discussões coletivas, exposição de ideias, além de incentivar o protagonismo juvenil" (ALVES; MARTIN, 2016a, p. 391). Destaque-se, por um lado, que a autoria ou os indícios de autoria seriam desejáveis em uma gama bastante extensa de gêneros - como discutimos anteriormente, é preciso que a noção de autoria seja não somente mais explorada, mas também melhor definida. No material em questão, uma interpretação possível é que esse "exercício de autoria" estaria relacionado ao da "criatividade" - veja-se a primeira questão do 
Roteiro de Avaliação, que explicita ser a "criatividade" um critério para avaliação dessa produção. Por outro lado, o protagonismo juvenil, a princípio, não seria qualidade que se aparta do uso linguístico, ou se adiciona a ele, mas se constitui com ele - veja-se que as autoras usam "além de" no trecho que citamos anteriormente, sendo que seria mais adequado dizer que as trocas verbais, as discussões coletivas e a exposição de ideias e pontos de vista incentivam o protagonismo juvenil, essa qualidade do sujeito participativo e agente na construção do social. Mas, nessa nossa proposta, já se subentende uma compreensão responsiva (na forma como a compreende os estudos bakhtinianos) do conceito, com um novo tema, com os valores sobre o "sujeito ativo/cidadão" tal como se produzem sob a perspectiva dos documentos oficiais direcionados ao Ensino Médio.

Consideremos, enfim, as atividades de escrita de um conto, que se encontram no volume direcionado ao terceiro ano do Ensino Médio. As autoras apresentam duas propostas (dar continuidade a um trecho inicialmente fornecido; desenvolvimento de sinopse de filme), antecedidas de uma instrução para a redação do texto

Agora é sua vez de escrever um conto. Quando todos os textos da turma estiverem em sua versão final, eles podem ser reunidos em uma publicação, que será disponibilizada entre os demais alunos da escola e, posteriormente, doada à biblioteca escolar, a fim de que outras pessoas possam ler os contos produzidos.

Para isso, leia as propostas enunciadas a seguir. Qualquer que seja sua escolha, você deverá:

- determinar qual será o conflito central da história;

- optar por um foco narrativo;

- criar os personagens necessários, estabelecendo seu perfili

- estabelecer as características do espaço onde a história irá ocorrer;

- considerar a possibilidade de explorar tanto o tempo cronológico quanto o tempo psicológico em seu texto;

- criar um título para seu conto.

Lembre-se também de que o conto deve apresentar verossimilhança, ou seja, ter uma coerência interna [...] (ALVES; MARTIN, 2016c, p.163).

Assim, o "acabamento estético" (BAKHTIN, 2000 [1953-1954]) que o autor daria ao conto estaria relacionado à sua organização interna; as autoras não produzem uma discussão sobre o público leitor, a linguagem esperada por ele, as expectativas em relação ao tratamento do tema. Em ambas, destaca-se a necessidade de se manter a verossimilhança, mas não a relação do autor com o interlocutor previsto ou com "a vida". Nessas propostas, claramente a concepção de literatura (e dos gêneros literários, portanto) interfere diretamente nas atividades propostas, que, no aspecto da "situacionalidade" de que vimos falando, são pouco desenvolvidas, apesar de se propor uma "situação de leitura" - organização de livro e disponibilização na biblioteca.

Um último aspecto na coleção que desejamos discutir aqui é a maneira como se organizam os capítulos dedicados à produção de textos e como ela interfere nas 
atividades de escrita propostas. Como exposto, a obra se compõe de três volumes divididos em unidades, que por sua vez se subdividem em capítulos, sendo o último capítulo de cada unidade destinado à produção de textos, em uma espécie de "fechamento" da unidade. Os capítulos destinados à produção de textos têm essa destinação sinalizada em seu título e se dedicam ao estudo de um gênero; esses capítulos, em sua maioria, se organizam em três partes, assim demarcadas: "Sobre o gênero"; "Produção do gênero"; "A dimensão da oralidade". Essa organização da coleção já deixa claro que a produção de textos está direcionada pelo estudo dos gêneros, tomados como conteúdo de ensino. Assim, nesses capítulos, as práticas de leitura e escrita são produzidas pelo "mote" do gênero: leem-se textos de um gênero determinado para se redigirem textos sobre esse mesmo gênero - é um exercício de aprender a ler e escrever gêneros. A integração entre leitura e escrita no capítulo dedicado à produção textual se dá pelo gênero em comum nas duas atividades e não pelo assunto abordado nos textos. Essa organização do material didático já indicia que as questões relativas aos gêneros ganham destaque e suplantam a preocupação com a construção de um projeto de dizer do autor do texto a ser produzido.

\section{CONSIDERAÇÕES FINAIS}

Após as considerações feitas, é preciso destacar que as propostas de produção textual analisadas são antecedidas de textos para leitura, mas não sobre as mesmas temáticas acerca das quais se vai escrever, o que esvazia o espaço da sala de aula de um debate que auxilia uma tomada de posição por parte do aluno e que propicia a construção de um projeto de dizer acerca de uma temática. Assim, as típicas "coletâneas de textos" foram substituídas por um novo modelo de "proposta do gênero", mas se houve ganho na preocupação com a "situacionalidade"/ "contextualização" da proposta de escrita, ainda há o que melhorar nessas práticas.

Um caminho possível seria considerar o gênero como o faz Bakhtin e o Círculo: composto por enunciados concretos que refletem e refratam valores sociais em uma determinada esfera de atividade, é necessariamente marcado axiologicamente e pelo projeto de dizer de um sujeito que se move em direção ao outro, seu interlocutor. Assim, o gênero é constituído por aspectos como forma composicional e estilo, mas esses aspectos são definidos pela forma arquitetônica, e nesse sentido é que é pensado como "um todo de sentido". Assim considerado, o gênero (discursivo) não se dissocia dos sujeitos e valores, sem eles perde a relação com a vida e se torna forma inerte e muda. 
Considerar gênero nessa perspectiva produziria um novo tema para a escrita escolar - encaminharia as atividades de ensino/aprendizagem da escrita para veredas em que se devolveria realmente a palavra ao sujeito na escola. Nesse espaço, poderia ser interessante desenvolver o protagonismo social a partir e com o uso da linguagem, e poderia ser interessante construir caminhos para se reforçar a ação sobre o outro com os indícios de autoria. Dessa forma, as atividades de escrita ganham a dimensão do dizer, que sem dúvida atingem a dimensão do fazer.

\section{$\overline{\text { REFERÊNCIAS }}$}

ALVES, R. H.; MARTIN, V. L. (2016a). Veredas da Palavra. Manual do Professor. São Paulo, Ática, v. 1.

ALVES, R. H.; MARTIN, V. L. (2016b). Veredas da Palavra. Manual do Professor. São Paulo, Ática, v. 2.

ALVES, R. H.; MARTIN, V. L. (2016c). Veredas da Palavra. Manual do Professor. São Paulo, Ática, v. 3.

BAKHTIN, M. (1952-1953). Os gêneros do discurso. In: BAKHTIN. M. Estética da criação verbal. Tradução de Maria Ermantina Galvão. 3. ed. São Paulo: Martins Fontes, 2000.

BAKHTIN, M. (1920-1924). Para uma filosofia do ato responsável. Tradução de V. Miotello e C. A. Faraco. São Carlos: Pedro \& João Editores, 2010.

ABAURRE, M. B.; FIAD, R. S.; MAYRINK-SABINSON, M. L. T. (1997). Cenas de Aquisição da Escrita: o sujeito e o trabalho com o texto. Campinas: Mercado de letras.

BRAIT, B. (2000). PCNs, gêneros e ensino de língua: faces discursivas da textualidade. In: ROJO, R. (Org.) A Prática de Linguagem em Sala de Aula - Praticando os PCNs. Campinas: Mercado de Letras.

BRASIL, Secretaria de Educação Fundamental. (1997). Parâmetros Curriculares Nacionais: primeiro e segundo ciclos do ensino fundamental. Língua portuguesa. Brasília, Secretaria de Educação Fundamental.

BRASIL, Secretaria de Educação Fundamental. (2000a). Parâmetros Curriculares Nacionais: Ensino Médio. Parte II. Linguagens, Códigos e suas Tecnologias. Brasília, Secretaria de Educação Fundamental.

BRASIL, Secretaria de Educação Fundamental. (2000b). Parâmetros Curriculares Nacionais: Ensino Médio+. Orientações Educacionais Complementares aos Parâmetros 
Curriculares Nacionais. Linguagens, Códigos e suas Tecnologias. Brasília, Secretaria de Educação Fundamental.

BRASIL, Secretaria de Educação Básica. (2011). Guia de livros didáticos: PNLD 2012 - Língua Portuguesa. Brasília: Ministério da Educação, Secretaria de Educação Básica.

BRASIL, Ministério da Educação. (2012). RESOLUÇÃO Nº 2, DE 30 DE JANEIRO 2012.

BRASIL, INEP. (2013). A redação no Enem-2013. Guia do Participante. Brasília.

BRASIL, Secretaria de Educação Básica. (2014). Guia de livros didáticos: PNLD 2015 - Língua Portuguesa. Brasília: Ministério da Educação, Secretaria de Educação Básica.

BRASIL, Secretaria de Educação Básica. (2017). Guia de livros didáticos: PNLD 2018 - Língua Portuguesa. Brasília: Ministério da Educação, Secretaria de Educação Básica.

BRASIL, Secretaria de Educação Básica. Base Nacional Comum Curricular. Brasília, s/d.

BRASIL, INEP. (2018). Redação no Enem 2018. Cartilha do participante. Brasília, Diretoria de Avaliação da Educação Básica.

CASSANY, D.; CASTELLÀ, J. M. (2010). Aproximación a la literacidad crítica. Perspectiva, Florianópolis, v. 28, n. 2, 353-374.

COSTA VAL, M. G. (1991). Redação e textualidade. São Paulo: Martins Fontes, 1994.

DE LEMOS, C. T. G. (1977). Redações no vestibular: algumas estratégias. Cadernos de pesquisa, n. 23, São Paulo, Fundação Carlos Chagas.

DE LEMOS, C. T. G. (1988). Coerção e criatividade na produção do discurso escrito em contexto escolar: algumas reflexões. In: SÃO PAULO (Estado) Secretaria da Educação. Coordenadoria de Estudos e Normas Pedagógicas. Subsídios à proposta curricular de língua portuguesa para o $1^{\circ}$ e $2^{\circ}$ graus. São Paulo: SE/CENP. 3v.

FIAD, R. S.; MAYRINK-SABINSON, M. L. T. (1991). A escrita como trabalho. In: MARTINS, M. H. (org.) Questões de linguagem. São Paulo: Contexto.

FOUCAULT, M. (1969). O que é um autor? Tradução de António Fernando Cascais e Edmundo Cordeiro. Veja/Passagens, 1992.

FOUCAUlT, M. (1970). A ordem do discurso. Tradução de Laura Fraga de A. Sampaio. 7. ed. São Paulo, Loyola, 2001. 
GERALDI, J. W. (Org.) (1984). O texto na sala de aula: leitura \& produção. 2. ed. Cascavel: ASSOESTE.

GERALDI, J. W. (1991). Portos de passagem. São Paulo: Martins Fontes.

GERALDI, J. W. (1996). Convívio paradoxal com o ensino da leitura e escrita. Cadernos de Estudos Linguísticos, Campinas, (31):127-143.

GERALDI, J. W. (2010). A aula como acontecimento. São Carlos: Pedro \& João Editores.

KATO, M. A. (1985). O aprendizado da leitura. 4. ed. São Paulo: Martins Fontes, 1995.

KLEIMAN, A. (Org.) (1995). Os significados do letramento: uma nova perspectiva sobre a prática social da escrita. Campinas: Mercado de Letras.

KOMESU, F. C.; GALLI, F. (2016). Práticas de Leitura e escrita em contexto digital: autoria e(m) novos médiuns. Revista da ABRALIN, v.15, n.2, p. 165-185.

MENDONÇA, M. C. (2015). Práticas de escrita e subjetividade. Letras \& Letras (Online), v. 31, p. $43-55$.

MENDONÇA, M. C. (2016). O discurso sobre autoria na esfera didático-pedagógica: algumas considerações. Revista da ABRALIN, v. 15, p. 265-284.

MENDONÇA, M. C. (2019). A produção textual na esfera escolar: considerações sobre a "escrita como trabalho". Diálogo das Letras, Pau dos Ferros, v. 8, n. 1, p. 3-15.

MEURER, J. L.; BONINI, A.; MOTTA-ROTH, D. (Orgs.). (2005). Gêneros: teorias, métodos, debates. São Paulo, Parábola editorial.

ONG, W. J. (1982). Orality and literacy: the technologizing of the world. London: Methuen.

ORLANDI, E. P. (1988). Discurso e leitura. São Paulo: Cortez; Campinas: Editora da Unicamp.

PÉCORA, A. B. (1977). Estudo do período: uma proposta pragmática. Cadernos de Pesquisa. Campinas, UNICAMP/IEL, n. 23.

PÉCORA, A. B. (1983). Problemas de redação. São Paulo: Martins Fontes.

POSSENTI, S. (1993). Estilo e aquisição da escrita. In: Estudos Linguísticos, XXII. Anais de Seminários do Grupo de Estudos Linguísticos do Estado de São Paulo (GEL), São Paulo, Jaú.

POSSENTI, S. (2002). Indícios de autoria. Perspectiva, Florianópolis, v.20, n.01, p.105-124. 
POSSENTI, S. (2013). Notas sobre a questão da autoria. Matraga, Rio de Janeiro, v.20, n.32.

ROJO, R. (2001). A teoria dos gêneros em Bakhtin: construindo uma perspectiva enunciativa para o ensino de compreensão e produção de textos na escola. In: BRAIT, B. (Org.) Estudos enunciativos no Brasil: histórias e perspectivas. Campinas: Pontes; São Paulo: Fapesp.

ROJO, R. (2005). Gêneros do discurso e gêneros textuais. In: MEURER, J. L.; BONINI, A.; MOTTA-ROTH, D. (Orgs.) Gêneros: teorias, métodos, debates. São Paulo, Parábola editorial.

SOARES, M. (1985). As muitas facetas da alfabetização. Cadernos de pesquisa. Fundação Carlos Chagas, São Paulo, n. 52, p. 19-24.

SOARES, M. (1995). Língua escrita, sociedade e cultura: relações, dimensões e perspectivas. Revista brasileira de educação, n. 0 .

SOARES, M. (2015). Alfabetização e letramento. São Paulo: Contexto.

STREET, B. (1994). Perspectivas interculturais sobre o letramento. Filologia e Linguística Portuguesa, n. 8, p. 465-488, 2006.

STREET, B. (2003). What's "new" in New Literacy Studies? Critical approaches to literacy in theory and practice. Current Issues in Comparative Education, Teachers College, Columbia University, Vol. 5 (2).

THE NEW LONDON GROUP. (1996). A pedagogy of multiliteracies: designing social futures. The Harvard educational review, v. 1, n. 66, p. 60-92. Disponível em http://www. sfu.ca/ decaste/newlondon.htm. Acesso em 30/06/19.

VOLÓCHINOV, V. (1929). Marxismo e filosofia da linguagem. Problemas fundamentais do método sociológico na ciência da linguagem. 1. ed. Tradução, Ensaio Introdutório, Glossário e Notas de S. V. C. Grillo e E. V. Américo. São Paulo: Editora 34, 2017.

VOLOCHÍNOV, V. (1930) A construção da enunciação. In: VOLOCHÍNOV. V. A construção da enunciação e outros ensaios. Organização, tradução e notas: João Wanderley Geraldi. São Carlos: Pedro \& João Editores, 2013.

Recebido: 30/06/2019

Aceito: 1/10/2019

Publicado: 7/10/2019 